\title{
Isokinetic muscle torque and endurance in limbs and trunk in children and adolescents: A longitudinal study
}

\author{
Manne Godhe ${ }^{\sharp}$, Torbjorn Helge ${ }^{\sharp}$, Artur Forsberg, Eddy Karlsson", , and Björn Ekblom \\ Astrand Laboratory of Work Physiology, The Swedish School of Sport and Health Sciences (GIH), Stockholm, Sweden \\ \#Authors contributed equally \\ †Diceased
}

\begin{abstract}
Purpose: To measure isokinetic peak torque during elbow, knee and trunk extension and flexion and muscle endurance during elbow and knee extension.

Method: Muscle endurance and peak torque were measured using Cybex methodology in totally 115 boys and 48 girls from 8 to 15 years of age most of them for five years.

Results: Knee muscle endurance was mainly unchanged while elbow fatigue index was lightly reduced from 11 to 15 years in both sexes with no difference between sexes. From the youngest ages to adolescence peak absolute (N.m) and normalized (N.m/kg body mass) torque increases in all measures with highest increase in the trunk and lowest in elbow activities. During elbow activity boys are stronger than girls from age 11 . For trunk and knee activity the sex differences start at age 14 years. Knee, elbow and trunk extension/flexion ratios as well as knee/elbow both extension and flexion ratios are mainly unchanged with increasing age with no differences between sexes.
\end{abstract}

Conclusion: Data indicate that elbow isokinetic strength and endurance profile is partly different from corresponding data during knee and trunk activity.

\section{Introduction}

Isometric muscle strength in children and adolescents have been measured since long. Most studies have shown that muscle strength increases with advanced age and is not different between girls and boys up to about early adolescence. Thereafter, muscle isometric strength in boys is higher than in age-equivalent girls. Normalizing data by dividing torque with body mass does not change these conclusions. Studies using isokinetic methodology have shown about the same [1-5]. Most of these studies have been cross-sectional, but there are also longitudinal studies in which individual torque values during some years from 8 to 15 years have been measured [5-10]. In these studies, knee and elbow torque is studied during extension and flexion. Trunk isokinetic torque has been measured in a few [11-13]. Studies on extension/flexion torque ratio in limbs and trunk as well as upper and lower body (knee vs elbow) extension and flexion torque ratios, respectively with increasing age in both sexes seem to be sparse $[14,15]$.

Isokinetic muscle endurance, an important aspect of physical performance, is much less studied in children and adolescents. Relative endurance measured as torque decline during consecutive extension contractions is depending on the percent fast twitch muscle fibers and peak muscle torque at the first contraction [15-17]. Several cross-sectional studies have reported that fatigue index is higher in young boys and girls compared to adults mainly due to higher initial peak muscle torque in the latter [18-21]. There seem to be no major difference in fatigability between sexes in young ages (10 - 12 years) during isokinetic knee flexion and extension or plantar flexion [22,23]. Furthermore, Kawakami, et al. [24] reported no difference in force decline between consecutive extension and flexion elbow contractions.

Although the present study was carried out during the beginning of the 1980-ies, the isokinetic muscle torque in limbs and trunk as well as endurance in limbs in children and adolescents of different ages is still not fully described. Therefore, this study was carried out as a combination of a longitudinal (five years) and cross-sectional set-up in order to obtain data on trunk, elbow and knee peak isokinetic torque values during flexion and extension and also muscle endurance during 50 consecutive elbow and knee extension in boys and girls 8 to 15 years of age. In this publication we report: age and sex mean peak absolute $(\mathrm{N} \cdot \mathrm{m})$ and normalized $(\mathrm{N} \cdot \mathrm{m} / \mathrm{kg}$ body mass) torque values $\pm \mathrm{SD}$ during extension and flexion in the trunk, elbow and knee; the extension and flexion peak torque ratio in these three measures; the knee/elbow ratio of both flexion and extension; relative muscle endurance during both elbow and knee extension.

\section{Subjects}

Boys and girls in the $2^{\text {nd }}, 5^{\text {th }}$ and $8^{\text {th }}$ grade in one school were invited to participate in this five-year study. Thus, children in the $2^{\text {nd }}$ grade participated during five years from age 8 to 12 and children in the $5^{\text {th }}$ grade from age 11 to 15 , while the adolescents in $8^{\text {th }}$ grade participated only during two years from age 14 to 15 . Totally 48 girls and 115 boys were involved, of which 24 girls ( 6 from the low grade and 16 from the middle grade) and 36 boys (11 from the low grade and 25 from middle grade) participated during all five years, resulting in a total of 201 visits by girls and 362 by boys in the laboratory - for anthropometric data see Table 1.

Correspondence to: Eddy Karlsson, Astrand Laboratory of Work Physiology, The Swedish School of Sport and Health Sciences (GIH), Stockholm, Sweden, E-mail: Bjorn.Ekblom@gih.se

Key words: cybex, sex differences, elbow, knee, trunk flexion, extension

Received: December 01, 2019; Accepted: December 11, 2019; Published: December 16, 2019 
Table 1. Antropometric data

\begin{tabular}{|c|c|c|c|c|c|}
\hline Age (yr) & $n$ & Height (cm) & Weight (kg) & BMI & $\begin{array}{c}\text { Percent } \\
\text { bodyfat }(\%)\end{array}$ \\
\hline \multicolumn{6}{|l|}{ Boys } \\
\hline 8 & 24 & $131,1 \pm 6,37$ & $28,6 \pm 5,66$ & $16,5 \pm 2,34$ & $16,2 \pm 5,69$ \\
\hline 9 & 25 & $137,9 \pm 7,95$ & $33,1 \pm 7,91$ & $17,2 \pm 2,79$ & $17,2 \pm 6,71$ \\
\hline 10 & 28 & $143,1 \pm 7,78$ & $37,2 \pm 9,30$ & $17,9 \pm 3,15$ & $18,7 \pm 7,13$ \\
\hline 11 & 59 & $149,7 \pm 7,91$ & $40,7 \pm 8,40$ & $18,0 \pm 2,55$ & $19,0 \pm 6,15$ \\
\hline 12 & 51 & $155,9 \pm 8,72$ & $44,4 \pm 9,32$ & $18,1 \pm 2,69$ & $18,5 \pm 6,35$ \\
\hline 13 & 42 & $162,3 \pm 9,76$ & $50,8 \pm 10,77$ & $19,1 \pm 2,52$ & $17,7 \pm 6,26$ \\
\hline 14 & 63 & $170,5 \pm 8,36$ & $57,1 \pm 9,83$ & $19,2 \pm 3,39$ & $15,7 \pm 7,08$ \\
\hline 15 & 60 & $173,7 \pm 8,92$ & $61,3 \pm 8,93$ & $20,3 \pm 2,55$ & $14,8 \pm 6,54$ \\
\hline \multicolumn{6}{|l|}{ Girls } \\
\hline 8 & 9 & $133,1 \pm 3,86$ & $29,2 \pm 6,20$ & $16,4 \pm 2,89$ & $18,2 \pm 5,19$ \\
\hline 9 & 10 & $139,9 \pm 4,41$ & $31,7 \pm 5,55$ & $16,1 \pm 2,30$ & $16,0 \pm 4,88$ \\
\hline 10 & 13 & $145,0 \pm 6,36$ & $34,9 \pm 6,46$ & $16,6 \pm 2,42$ & $17,8 \pm 5,61$ \\
\hline 11 & 35 & $151,2 \pm 7,43$ & $40,0 \pm 6,52$ & $17,5 \pm 2,15$ & $19,3 \pm 4,85$ \\
\hline 12 & 37 & $156,2 \pm 6,97$ & $44,8 \pm 7,35$ & $18,3 \pm 2,38$ & $19,1 \pm 5,10$ \\
\hline 13 & 30 & $161,7 \pm 6,55$ & $50,0 \pm 8,24$ & $19,0 \pm 2,47$ & $20,2 * \pm 5,29$ \\
\hline 14 & 29 & $165,2^{*} \pm 5,55$ & $54,9 \pm 8,49$ & $20,1 \pm 2,72$ & $22,0 * \pm 5,61$ \\
\hline 15 & 26 & $165,8^{*} \pm 5,59$ & $56,2 * \pm 8,69$ & $20,4 \pm 2,94$ & $22,6^{*} \pm 5,13$ \\
\hline
\end{tabular}

\section{Procedure and methods}

All tests were carried out with the same procedure, methods and researchers during the month of October from 1980 to 1984.

Body height and weight were measured in light clothes using standardized methods to the nearest $0,1 \mathrm{~cm}$ and $0,1 \mathrm{~kg}$, respectively. Subscapular and triceps skinfold thickness on both sides were measured with a skinfold caliper. Body fat percent was calculated according to Slaughter, et al. [25]. Thereafter the participants performed a warmup on a Monark bicycle before muscle measurements. The isokinetic muscle torque in limbs and trunk was measured using three Cybex 6000 dynamometers (Cybex-Lumex Ink, Ronkonkoma, New York), adapted for the type of measurements. During knee extension- and flexion measurements of the right leg a strap fixed both the thigh and the chest to the seat to which the Cybex-apparatus was applied. During elbow extension- and flexion measurements the participant was sitting on a chair in front of a table. The right elbow was placed on a marking on the table with the hand holding the handle of the Cybex-apparatuses, which was applied to the table. A strap fixed the chest to the chair so that no muscle movements of the upper body or the left arm could be added to the measurement. During these two measurements the knee and elbow joint rotation center was in line with the axis of the Cybexapparatus. The best result of two attempts of both flexion and extension during speeds of 15,60,120, 180 and 240 degrees/sec, respectively, was used. The relative endurance in both the elbow and knee muscles was evaluated as the percent peak torque decline from the first to the $50^{\text {th }}$ consecutive extension contraction at a speed of 180 degrees/sec according to Thorstensson and Karlsson [26]. A researcher guided the participant to keep a constant contraction speed.

In order to measure the trunk extension and flexion torque the main part of the Cybex dynamometer was fixed under a non-moving part of a specially constructed bench with the moving arm of the dynamometer under the moving part of the bench (Figure 1). The axis of the Cybexdynamometer was placed below the small opening between the two parts of the bench. The participant was lying on its right side with the knees fixed with straps over the thigh and lower leg to the non-moving part of the bench and the chest with a strap to the moving part of the bench. The subject hip joint was placed above the Cybex axes. The best result of two measurements of extension and flexion at one contraction speed, 15 degrees/sec, was used.

During all parts of the investigation the participants received strong verbal encouragement through the whole range of motion.

This study was carried out during five years from 1980 to 1984 . At this time Ethical permission was not necessary for this type of study. However, for publication purpose the local Regional Ethics Committee in Stockholm approved this study in 2017. At the time informed oral consent regarding the children's participation was obtained from parents or legal guardians.

\section{Statistics}

All statistical tests were performed in SPSS, version 24, (SPSS Inc. Chicago, IL, USA). Data are presented as means and standard deviation (SD). Independent sample t-tests were used to compare the mean scores between girls and boys. The significance level was set to $\mathrm{p}<0.05$.

A one-way between-groups analysis of variance was conducted to explore muscle fatigue differences between age groups over time. Pearson correlation analysis was used to assess the associations between the different muscle torque measurements.

\section{Methodological considerations}

The same three Cybex apparatus were used during the five years for all children. Thus, no modifications related to body size were made [27]. Furthermore, we have not considered any possible differences in torque between dominant and non-dominant arm or leg [1].

In this publication values, from only one contraction speed, 60 degrees/sec during limb actions, are presented since conclusions drawn from other contraction speeds are similar to those drawn from the speed chosen. Pilot trunk tests showed that, compared to faster speeds, the low contraction speed of 15 degrees/sec chosen was most reliable and had the lowest error of the method. For elbow and knee endurance the speed of 180 degrees/sec was used according to Thorstensson and Karlsson [26], since a slower speed may cause premature fatigue, which could stop activity before the $50^{\text {th }}$ contraction. All children and adolescents performed all 50 contractions in both the knee and elbow endurance test during the five years.

\section{Results}

\section{Anthropometrics}

Body height and weight, calculated BMI (weight in $\mathrm{kg} /$ height in $\mathrm{m}^{2}$ ) and percent body fat are listed in Table 1 . From age 13 years there is a significant difference in body fat percent between boys and girls.

\section{Muscle strength}

There is a consistently greater extension than flexion absolute and normalized peak torque $(\mathrm{p}<0,05)$ during elbow, knee and trunk activity in both sexes.

Differences between boys and girls during elbow extension and flexion absolute peak torque (N.m) starts at age 10, while for the knee corresponding peak torque differences start at age 14. For the trunk, a sex difference is only seen at age 15 for extension and at age 14 and 15 for flexion.

Peak elbow extension and flexion torque values normalized for body mass (N.m/kg body mass) are higher in boys than girls from age 10 and 11 and older, respectively (Table 2). Peak torque normalized values are 
Table 2. Trunk, elbow and knee flexion and extension peak isometric muscle torque $(\mathrm{Nm})$ and $\mathrm{N} \cdot \mathrm{m} / \mathrm{kg}$ body mass times 100 in different ages in boys and girls. $* \mathrm{P}<0,05$ between boys and girls

\begin{tabular}{|c|c|c|c|c|c|c|c|}
\hline Age (yrs) & $n$ & \multicolumn{2}{|c|}{ Trunk } & \multicolumn{2}{|c|}{ Elbow } & \multicolumn{2}{|c|}{ Knee } \\
\hline \multicolumn{8}{|l|}{ a. $\mathrm{N} \cdot \mathrm{m}$} \\
\hline \multicolumn{2}{|c|}{ Boys } & Flexion & Extension & Flexion & Extension & Flexion & Extension \\
\hline 8 & 24 & $62,7 \pm 22,1$ & $68,9 \pm 26,9$ & $10,4 \pm 2,3$ & $13,1 \pm 4,1$ & $37,5 \pm 27,8$ & $53,3 \pm 17,0$ \\
\hline 9 & 25 & $70,2 \pm 25,6$ & $87,0 \pm 31,9$ & $11,3 \pm 3,6$ & $14,9 \pm 4,1$ & $31,3 \pm 14,9$ & $50,4 \pm 9,9$ \\
\hline 10 & 28 & $75,0 \pm 30,4$ & $111,3 \pm 37,3$ & $13,1 \pm 3,1$ & $18,4 \pm 4,6$ & $39,0 \pm 21,5$ & $66,3 \pm 17,2$ \\
\hline 11 & 59 & $91,8 \pm 27,41$ & $116,3 \pm 44,1$ & $16,7 \pm 4,4$ & $22,1 \pm 4,5$ & $43,8 \pm 21,9$ & $77,3 \pm 13,2$ \\
\hline 12 & 51 & $100,9 \pm 29,6$ & $129,4 \pm 42,9$ & $19,5 \pm 5,2$ & $24,7 \pm 5,3$ & $51,9 \pm 24,7$ & $92,1 \pm 15,5$ \\
\hline 13 & 42 & $114,6 \pm 39,1$ & $174,1 \pm 50,9$ & $23,7 \pm 7,1$ & $30,0 \pm 8,2$ & $63,3 \pm 31,7$ & $112,3 \pm 17,4$ \\
\hline 14 & 63 & $165,7 \pm 49,1$ & $199,9 \pm 56,6$ & $32,5 \pm 8,3$ & $37,6 \pm 8,3$ & $73,9 \pm 29,7$ & $123,7 \pm 16,9$ \\
\hline 15 & 60 & $185,8 \pm 54,5$ & $236,4 \pm 63,5$ & $35,6 \pm 8,2$ & $40,9 \pm 10,2$ & $86,8 \pm 34,1$ & $145,5 \pm 20,9$ \\
\hline \multicolumn{2}{|c|}{ Girls } & Flexion & Extension & Flexion & Extension & Flexion & Extension \\
\hline 8 & 9 & $54,3 \pm 12,6$ & $71,8 \pm 29,1$ & $8,6 \pm 2,3$ & $11,6 \pm 1,5$ & $32,1 \pm 13,9$ & $49,0 \pm 12,8$ \\
\hline 9 & 10 & $65,0 \pm 9,35$ & $82,2 \pm 21,8$ & $9,5 \pm 2,6$ & $13,0 \pm 2,6$ & $29,2 \pm 13,2$ & $54,4 \pm 6,6$ \\
\hline 10 & 13 & $68,6 \pm 22,6$ & $92,7 \pm 21,7$ & $11,1 \pm 3,2$ & $14,9^{*} \pm 3,2$ & $34,8 \pm 13,4$ & $66,3 \pm 7,7$ \\
\hline 11 & 35 & $84,4 \pm 27,3$ & $111,6 \pm 39,9$ & $14,5^{*} \pm 3,9$ & $19,7 * \pm 3,9$ & $39,5 \pm 22,3$ & $76,7 \pm 10,6$ \\
\hline 12 & 37 & $109,2 \pm 30,4$ & $135,6 \pm 42,3$ & $15,8^{*} \pm 5,4$ & $21,7^{*} \pm 5,4$ & $49,5 \pm 18,2$ & $86,6 \pm 14,0$ \\
\hline 13 & 30 & $106,1 \pm 26,8$ & $177,1 \pm 44,5$ & $19,3 * \pm 6,6$ & $25,8^{*} \pm 6,7$ & $57,3 \pm 18,1$ & $102,9 \pm 14,4$ \\
\hline 14 & 29 & $144,3^{*} \pm 36,2$ & $173,7 \pm 44,6$ & $21,9 * \pm 4,9$ & $28,3 * \pm 4,9$ & $61,9 * \pm 16,9$ & $110,0^{*} \pm 12,8$ \\
\hline 15 & 26 & $149,4 * \pm 25,4$ & $199,9 * \pm 41,9$ & $21,5^{*} \pm 5,3$ & $26,2 * \pm 5,3$ & $66,4 * \pm 17,9$ & $116,7^{*} \pm 12,2$ \\
\hline \multicolumn{8}{|l|}{ b. $\mathrm{N} \cdot \mathrm{m} / \mathrm{kg} \times 100$} \\
\hline \multicolumn{2}{|c|}{ Boys } & Flexion & Extension & Flexion & Extension & Flexion & Extension \\
\hline 8 & 24 & $219 \pm 61$ & $237 \pm 66$ & $37 \pm 9$ & $46 \pm 9$ & $128 \pm 46$ & $144 \pm 46$ \\
\hline 9 & 25 & $215 \pm 64$ & $263 \pm 70$ & $34 \pm 8$ & $45 \pm 8$ & $94 \pm 18$ & $124 \pm 23$ \\
\hline 10 & 28 & $200 \pm 57$ & $299 \pm 62$ & $36 \pm 10$ & $50 \pm 11$ & $105 \pm 34$ & $142 \pm 41$ \\
\hline 11 & 59 & $227 \pm 56$ & $283 \pm 77$ & $41 \pm 9$ & $55 \pm 11$ & $107 \pm 24$ & $151 \pm 27$ \\
\hline 12 & 51 & $202 \pm 78$ & $259 \pm 100$ & $44 \pm 8$ & $56 \pm 12$ & $116 \pm 27$ & $167 \pm 27$ \\
\hline 13 & 42 & $226 \pm 62$ & $343 \pm 70$ & $47 \pm 10$ & $59 \pm 11$ & $125 \pm 23$ & $184 \pm 25$ \\
\hline 14 & 63 & $290 \pm 71$ & $349 \pm 80$ & $57 \pm 14$ & $65 \pm 11$ & $129 \pm 22$ & $182 \pm 30$ \\
\hline 15 & 60 & $299 \pm 70$ & $381 \pm 82$ & $58 \pm 11$ & $66 \pm 13$ & 14124 & $204 \pm 27$ \\
\hline \multicolumn{2}{|c|}{ Girls } & Flexion & Extension & Flexion & Extension & Flexion & Extension \\
\hline 8 & 9 & $187 \pm 27$ & $244 \pm 76$ & $30 \pm 9$ & $41 \pm 7$ & $113 \pm 49$ & $139 \pm 63$ \\
\hline 9 & 10 & $209 \pm 38$ & $260 \pm 54$ & $30 \pm 8$ & $41 \pm 4$ & $93 \pm 21$ & $145 \pm 18$ \\
\hline 10 & 13 & $199 \pm 56$ & $272 \pm 59$ & $32 \pm 10$ & $43 * \pm 9$ & $102 \pm 23$ & $151 \pm 28$ \\
\hline 11 & 35 & $209 \pm 55$ & $276 \pm 83$ & $36^{*} \pm 8$ & $49 * \pm 8$ & $99 \pm 21$ & $142 \pm 29$ \\
\hline 12 & 37 & $239 * \pm 57$ & $304 * \pm 74$ & $35^{*} \pm 9$ & $48 * \pm 9$ & $111 \pm 26$ & $157 \pm 25$ \\
\hline 13 & 30 & $223 \pm 51$ & $349 \pm 91$ & $39 * \pm 7$ & $51 * \pm 8$ & $115 \pm 23$ & $167 * \pm 25$ \\
\hline 14 & 29 & $266 \pm 56$ & $330 \pm 86$ & $41 * \pm 9$ & $52 * \pm 9$ & $113 * \pm 19$ & $167 \pm 31$ \\
\hline 15 & 26 & $261 * \pm 70$ & $345 \pm 112$ & $38 * \pm 7$ & $47^{*} \pm 8$ & $120 * \pm 24$ & $171^{*} \pm 22$ \\
\hline
\end{tabular}

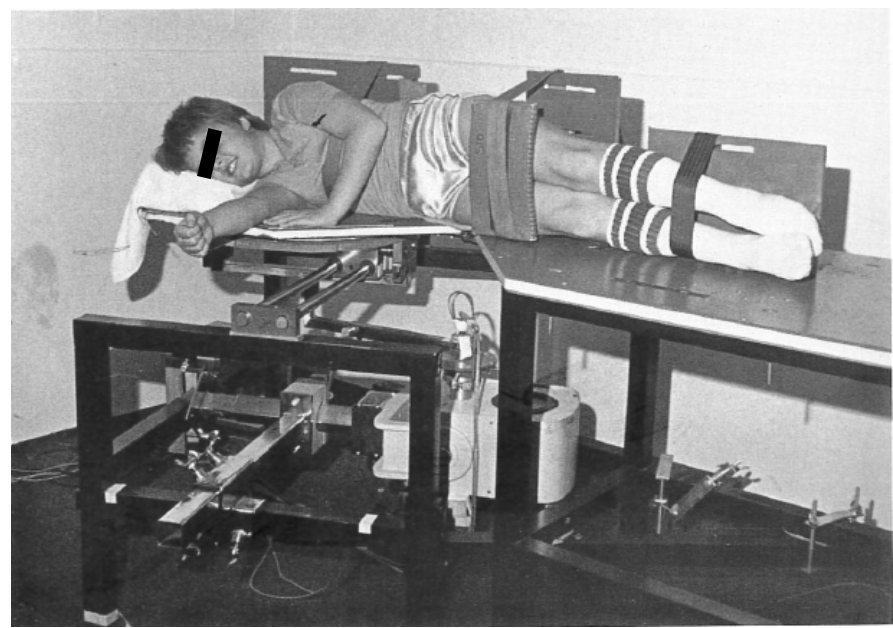

Figure 1. Measurement of trunk movement higher in boys than girls at age 13 and 15 in knee extension, and at age 14 and 15 in knee flexion. For trunk extension and flexion higher peak torque normalized values are found in boys compared to girls only at three points with regard to age groups; at age the $12^{\text {th }}$ and $15^{\text {th }}$ year age groups for flexion and in the $12^{\text {th }}$ year age group for extension. The increase in average absolute (N.m) values from the $8^{\text {th }}$ to the $15^{\text {th }}$ year age group is highest in the trunk, lowest in the elbow with the increase in knee activity in between these two measures. Normalizing data (N.m/body mass) reduces the rate of increase in all measurements in both sexes but does not change the rank order.

\section{Relation between extension and flexion}

Regarding the elbow extension/flexion ratio there is a significant decline from the $10^{\text {th }}$ year to the $15^{\text {th }}$ year age group in both boys and girls with no difference between sexes. Knee joint extension/flexion ratio increases from 8 to 10 years in both boys and girls. Thereafter no changes are seen with increasing age the from $10^{\text {th }}$ to the $15^{\text {th }}$ year age 
group with no difference between sexes. For trunk there are no changes in the extension/flexion ratio with increasing age with no significant differences between boys and girls.

\section{Upper vs lower limb muscle torque}

There is no change with increasing age in both sexes in the ratio between knee and elbow values of extension and flexion, respectively, which confirms the isometric data reported by Parker, et al. [15]. Boys have lower knee/elbow extension ratio than girls in all except the 8-year age group depending on the relatively higher elbow extension torque in boys compared to girls. There are no differences in knee/elbow flexion ratio in any age group between boys and girls.

\section{Muscle endurance}

For the knee the fatigue index is higher in the 8 to 10 year age groups compared to older ages in both sexes but from age 10 years and older there is no change in fatigue index with increasing age in neither boys or girls (Figure 2). In all ages except in the youngest two (8 and 9 years) boys are more fatique resistent than girls. For the elbow there is no change in fatique index between 8 to 11 years of age, but from age 11 to 15 there is a decline $(\mathrm{P}<0,05)$ in fatigue index in both boys and girls with no difference between sexes (Figure 2).

\section{Discussion}

The use of isokinetics for studying muscle torque in children and adolescents is fully accepted and reliable [1,21,26-32]. The overall conclusion from different peak torque values obtained during elbow and knee joint extension and flexion activities in this study are in line with most previous studies $[4,5,7-9,11]$. However, this study also presents a complete set of different ratios during limb and trunk activities in both sexes and all age groups from 8 to 15 years.

The novel data in the study is related to the muscle endurance. The isokinetic method used in this study for measuring muscle endurance is reported to be reliable [21]. For the knee joint we have no data to compare the higher fatigability index in children compared to corresponding in adults as reported in previous studies [17-20]. but our data show no trend of decreased fatigability during knee extension up to age 15 years in both sexes. There are significant differences, except in the 8-year age group, in knee muscle endurance between boys and girls in all age groups, boys being more fatigue resistant (Figure 2). This is somewhat surprising since knee peak torque is higher in boys in the $14^{\text {th }}$ and $15^{\text {th }}$ year age groups and, still, boys have a higher fatigue index than girls. A reduced fatigue index as seem in adults compared to children has been explained by higher percent of fast twitch muscle fibers and initial peak torque values in the latter [15,17-20,25]. However, we could not find any such relation between knee peak extension torque and fatigue index in any sex or age group.

The present study shows that there are some differences between elbow and knee muscle extension endurance. For the elbow opposite to the knee joint there is a small lowering of the elbow fatigue index from age 11 in boys and 12 in girls with no difference between boys and girls. This observation is in line with data from 10 to 12 -year age groups in previous reports $[13,17,22]$ but is surprising since the peak elbow extension torque values are higher in boys from the $11^{\text {th }}$ to the $15^{\text {th }}$ year age group (Table 2). In line with the knee joint endurance there is no relation between elbow peak extension torque and fatigue index in any age group. It should also be mentioned that there is no correlation between elbow and knee joint fatigue indexes in neither boys nor girls in any age group. Evidently, there is an obvious need for studying fatigability in both limbs in children and adolescents of both sexes.

Of special interest is that there is no significant difference in any age group between the mean values including those boys and girls, who participated during all five years and corresponding age mean crosssectional values, in which the longitudinal data are excluded. This means that age average values are fairly reliable compared to individual longitudinal data in this study. However, cross-sectional data cannot discover the individual developments. As seen in Figure 3 outlier values remain in about the same position in relation to the age group mean values from their $11^{\text {th }}$ up to the $15^{\text {th }}$ year even if there is larger spread in older ages. There is a strong correlation between the individual values at 11 and 15 years of age (strongest correlation found for knee extension $\mathrm{r}=0,834$ for boys, $\mathrm{p}<0,01)$. Thus, a strong or weak boy at 11 years of
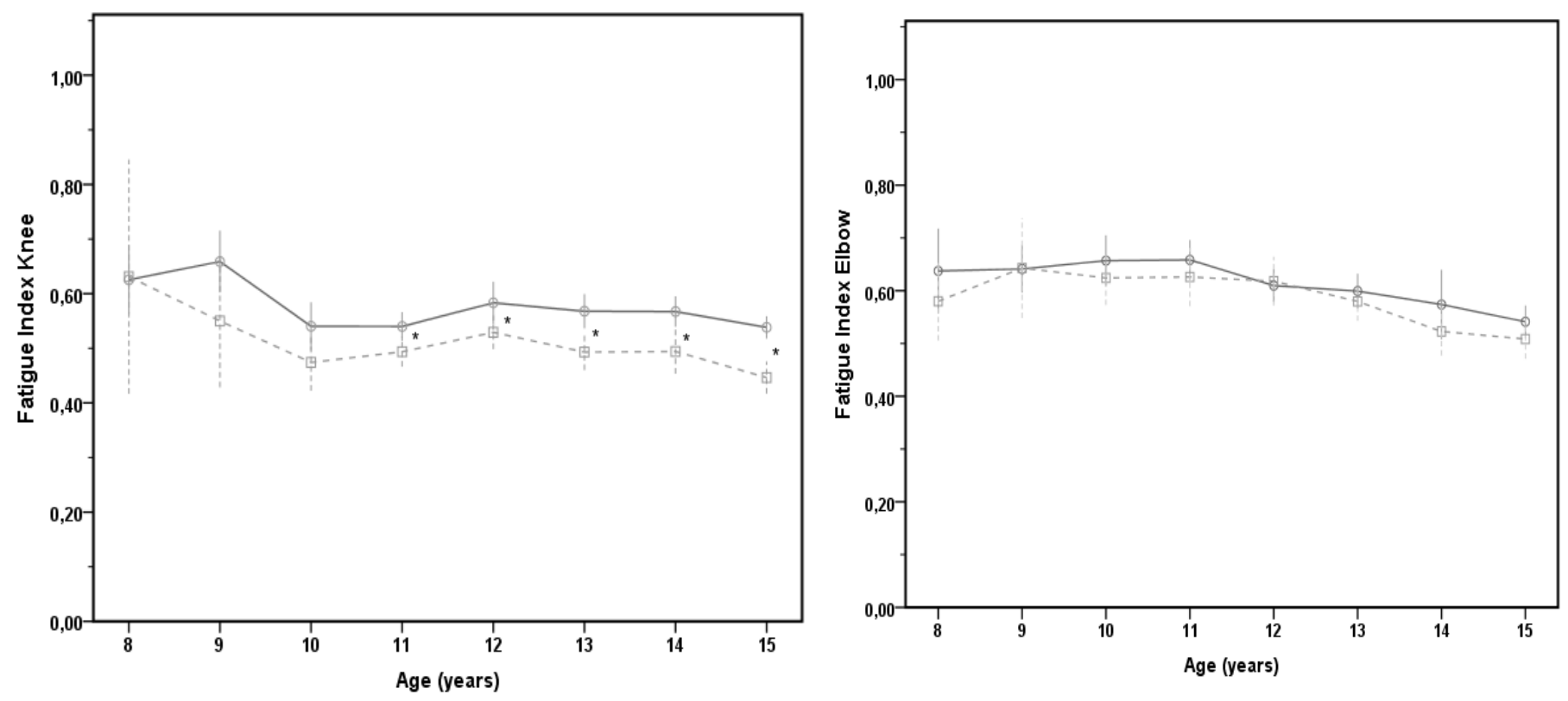

Figure 2. Knee extension fatigue index (A) and elbow extension fatique index (B) in boys (solid lines) and girls (dotted lines). ${ }^{*} \mathrm{P}<0,05$ between boys and girls 
a,
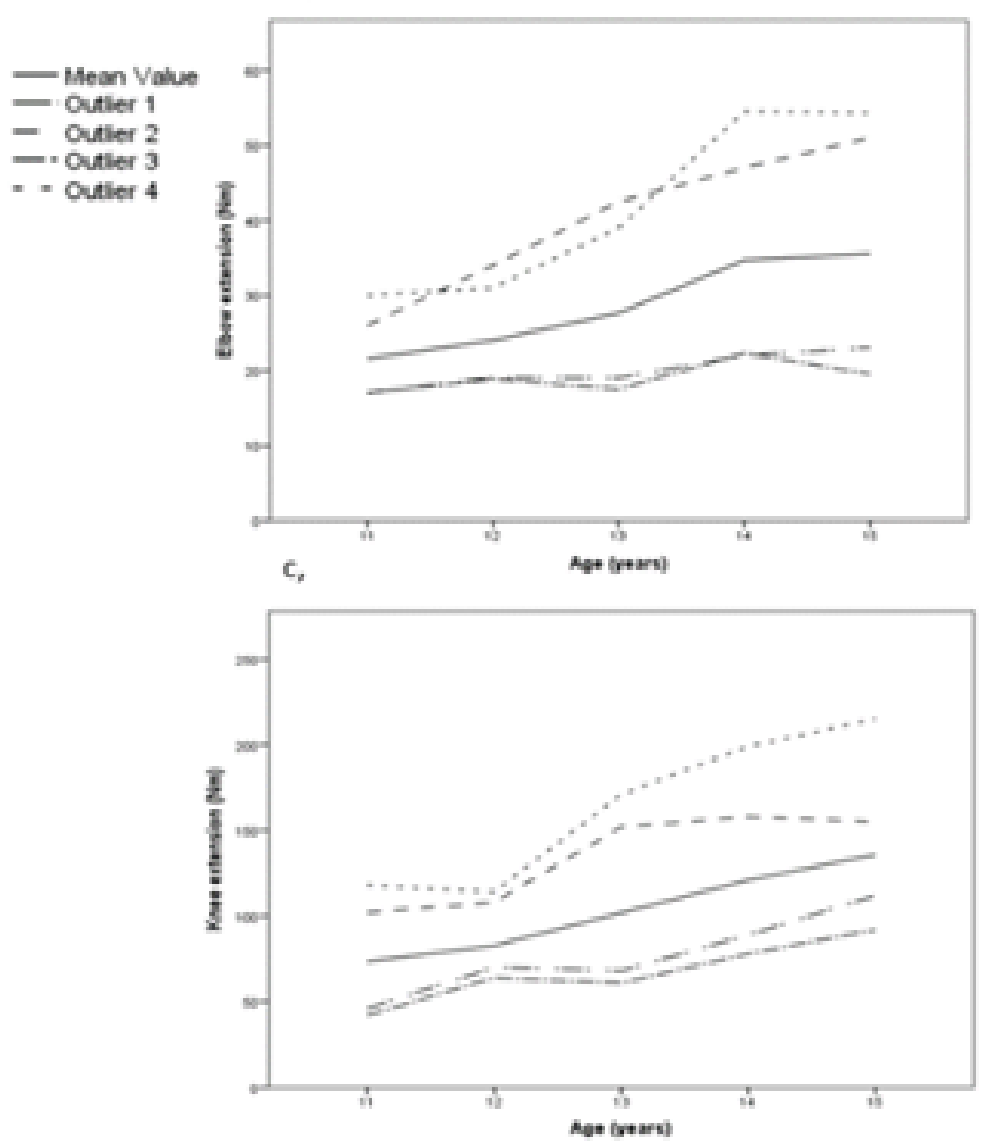

b,
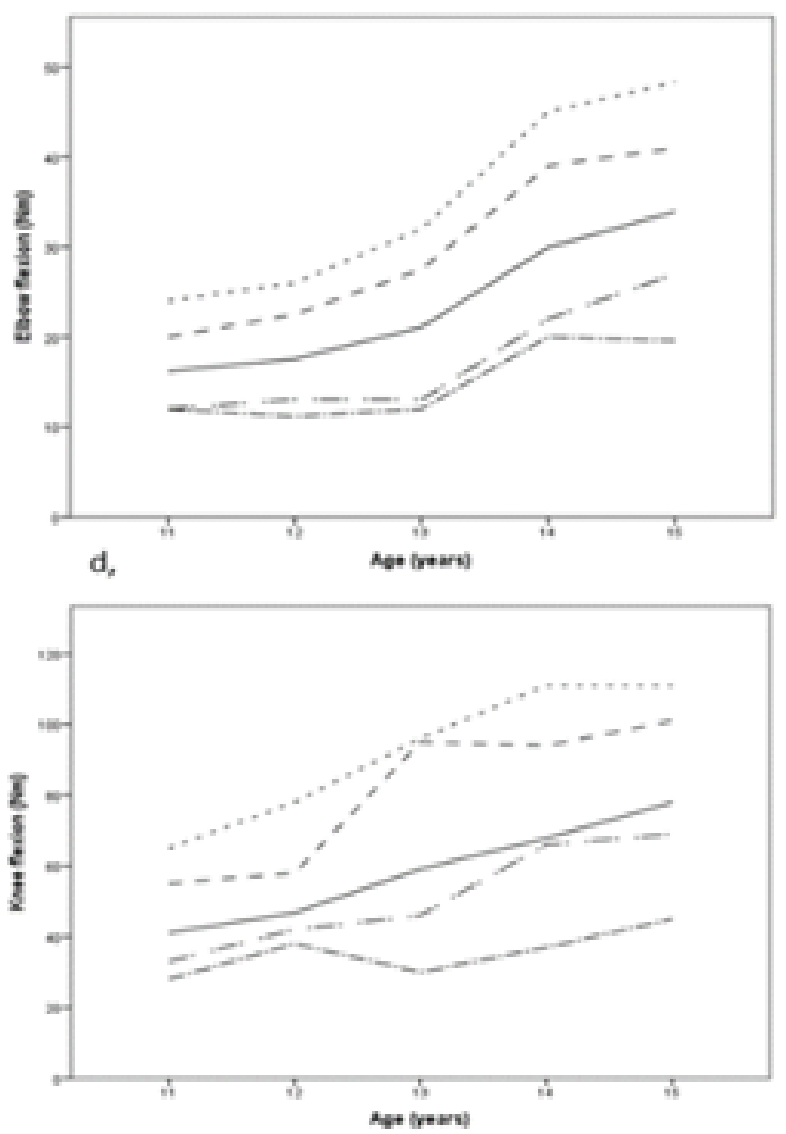

Figure 3. High and low values of peak torque during knee extension (a) and flexion (b) and elbow extension (c) and flexion (d) in boys at 11 years of age and during the following years up to 15 years of age ("outliers"). Full line age mean values

age is relative to age mean still a strong or weak boy at 15 years. The same corresponding correlation is found in girls. From an educational and health point of view a conclusion could be that the educational professionals should focus on weak boys and girls in young ages to prevent a low physical muscle performance and health in post-puberty ages.

This study indicates that there are some differences in peak torque and endurance between elbow on one hand and knee and trunk activity on the other. The difference between boys and girls in absolute and normalized data for elbow activity starts already at age 10 years compared to about 14 years for the trunk and knee activities. There is a lowering of elbow extension/flexion ratio with increasing age from age 10 years in both sexes, while there is no corresponding ratio change in knee or trunk. There is a decline in elbow fatigue index from the $11^{\text {th }}$ to the $15^{\text {th }}$ year in both boys and girls but there is no such decline in knee fatigue index in neither sex. There are no differences between boys and girls in fatigability during elbow activity but significant differences between sexes during knee endurance, boys being more fatigue resistant in all except one age group. There is a no relation between elbow and knee fatigability index. There are no reasons to believe that these differences between the three types of measurements could be of a systematic methodological origin.

The data in this study was collected during five consecutive years, from 1980 to 1984 . As shown by Tremblay, et al. [31] there has been a meaningful decrease in fitness level of Canadian children from 1981 to 2007-2009 (with a significant lower result in hand grip strength in all age groups 2007-2009 compared to 1981). A similar decline in Swedish children fitness level is also likely. The results in this study is therefore of interest for future comparisons and, furthermore, for follow-up studies of adult health in these participants.

\section{Conclusion}

Data indicate that elbow isokinetic strength and endurance profile is partly different from corresponding data during knee and trunk activity.

\section{Acknowledgements}

This study was supported by The Swedish Military Forces Research Authority (Grant \#AF9220916).

\section{References}

1. Henderssson RC, Howes CL, Erickson KL, Heere LM, DeMasi RA (1993) Knee flexorextensor strength in children. J Orthop Sports Phys Ther 18: 559-563.

2. Holm A, Fredriksen PM, Fosdahl M, Vollestad N (2008) A normative sample of isotonic and isokinetic muscle strength measurements in children 7 to 12 years of age. Acta Paedr 97: 602-607. [Crossref]

3. Ramos E, Fontera WR, Llopart A, Feliciano D (1998) Muscle strength and hormonal levels in adolescence; gender related differences. Int J Sports Med 19: 526-531.

4. Seger JY, Thorstensson A (2000) Muscle strength and electromyogram in boys and girls followed through puberty. Eur J Appl Physiol 81: 54-61. [Crossref] 
5. Sunnegardh J, Bratteby LE, Nordesjo LO, Nordgren B (1998) Isometric and isokinetic muscle strength, anthrpometry and physical activity in 8 and 13 year old Swedish children. Eup J Appl Physiol 58: 291-297. [Crossref]

6. Alexander J, Molnar GE (1973) Muscular strength in children: preliminary report on objective standards. Arch Phys Med Rehabil 54: 424-427.

7. Bassa E, Kotzamanidis D, Patikas D, Parachos I (2001) The effect of age on isokinetic concentric and eccentric moment of knee extensors- Isokinetics and exercise science 9: $155-161$.

8. De Ste Croix MB, Armstrong N, Welsman JR, Sharpe P (2002) Longitudinal changes in isokinetic leg strength in 10-14-year-olds. Ann Hum Biol 29: 50-62. [Crossref]

9. Holm I, Steen H, Olstad M (2005) Isokinetic muscle performance in growing boys from pre-teen to maturity. An eleven-year longitudinal study. Isokinetics and exercise science 13: 153-158.

10. Round JM, Jones DA, Honour JW, Nevell AM (1999) Hormonal factors in the development of diferences in strength between boys and girls during adolescence: a longitudinal study. Ann Hum Biol 26: 49-62.

11. Balague F, Damidot P, Nordin M, Parnianpour M, Waldburger M (1993) Crosssectional study of the isokinetic muscle trunk strength among school children. Spine 18: 208-214. [Crossref]

12. Burnett CN, Betts EF, King WM (1990) Reliability of isokinetic measurements of hip muscle torque in young boys. Phys Ther 70: 244-249.

13. Gilliam TB, Sady SP, Freedson PS, Villanacci J (1979) Isokinetic torque levels for high school football players. Arch Phys Med Rehabil 60: 110-114. [Crossref]

14. Parker DF, Round JM, Sacco P, Jones DA (1990) A cross-sectional survey of upper and lower limb strength in boys and girls during childhood and adolescence. Ann Hum Biol 17: 199-203.

15. Nilsson J, Tesch P, Thorstensson A (1977) Fatigue and EMG of repeated voluntary contractions in man. Acta Physiol Scand 101: 194-198.

16. Pincivero DM, Gear WS, Sterner RL (2001) Assessment of the reliability of high-intensity quadriceps femoris muscle fatigue. Med Sci Sports Exerc 33: 334-338. [Crossref]

17. De Ste Croix MBA, Deighan MA, Ratel S, Armstrong N (2009) Age- and sexassociated differences in isokinetic knee muscle endurance between young children and adults. App Physiol Nutr Metab 34: 725-731. [Crossref]

18. Halin R, Germain P, Bercier S, Kapitaniak B, Buttelli O (2003) Neuromuscula response of young boys versus men during sustained maximal contraction. Med Sci Sports Exerc 35: 1042-1048.
19. Kinehasa H, Okuyama H, Ikegawa S, Fukunaga T (1995) Fatigability during repetivie maximal knee extensions in 14-year-old boys. Eup J Appl Physiol Occup Physiol 72: $170-174$

20. Paraschos I, Hassani A, Bassa E, Hatzikotoulas K, Patikas D, et al. (2007) Fatigue differences between adults and prepubital males. Int J Sports Med 28: 958-963. [Crossref]

21. De Ste Croix MBA, Armstrong N, Welsman JR (2003) The reliability of an isokinetic knee muscle endurance test in children. Pediat Exerc Sci 15: 313-323.

22. Kotzamanidis C, Hatzikotoulas K, Dimitrios P, Eleni B (2006) Differences in fatigability between sexes during sustained submaximal contraction protocol in prepubertal children. J Sports Sci 24: 817-824. [Crossref]

23. Kawakami Y, Kanehisa H, Ikegawa S, Fukunaga T (1993) Concentric and eccentric muscle strength before, during and after fatigue in 13 year-old boys. Aep J Appl Physiol Occup Physiol 67: 121-124.

24. Slaughter MH, Lohman TG, Boileau RA, Horswill CA, Stillman RJ, et al. (1988) Skinfold equations for estimation of body fatness in children and youth. Hum Biol 60: 709-723. [Crossref]

25. Thorstensson A, Karlsson J (1976) Fatiguability and fibre composition of human skeletal muscle. Acta Physiol Scand 40: 12-16.

26. De Ste Croix MBA, Deighan MA, Armstrong N (2003) Assessment and interpretation of isokinetic muscle strength during growth and maturation. Sports Med 33: 727-743.

27. Kellis E, Baltzopoulos V (1995) Isokinetic eccentric exercise. Sports Med 19: 202-222. [Crossref]

28. Kellis E, Kellis S, Gerodimos V, Manou V (1999) Reliability of isokinetic concentric and eccentric strength in circumpubertal soccer players. Paedr Exerc Sci 11: 218-228.

29. Merlini L, Dell'Accio D, Granata C (1995) Reliability of dynamic strength knee muscle testing in children. J Orthop Sports Phys Ther 22: 73-76. [Crossref]

30. Molnar GE, Alexander J, Gutfeld N (1979) Reliability of quantitative strength measurements in children. Arch Phys Med Rehabil 60: 218-221. [Crossref]

31. Tremblay MS, Shields M, Laviolette M, Craig CL, Janssen I et al. (2010) Fitness of Canadian children and youth: results from the 2007-2009 Canadian Health Measures Survey. Health Reports 21: 7-20. [Crossref]

32. Vollestad NK (1997) Measurement of human muscle fatigue. J Neurosci Methods 74 219-227. [Crossref]

Copyright: (C2019 Godhe M. This is an open-access article distributed under the terms of the Creative Commons Attribution License, which permits unrestricted use, distribution, and reproduction in any medium, provided the original author and source are credited. 